\title{
Asymmetric Impact of Energy Utilization and Economic Development on Environmental Degradation in Somalia
}

\section{Abdimalik Ali Warsame ( $\square$ abdimalikali1995@gmail.com )}

Garaad Institute for Social Research and Development Studies https://orcid.org/0000-0001-6130-5607

\section{Samuel Asumadu Sarkodie}

Nord University Business School (HHN).

\section{Research Article}

Keywords: Energy, Economic growth, Environmental degradation, NARDL, Somalia

Posted Date: April 16th, 2021

DOl: https://doi.org/10.21203/rs.3.rs-378579/v1

License: (c) (1) This work is licensed under a Creative Commons Attribution 4.0 International License.

Read Full License

Version of Record: A version of this preprint was published at Environmental Science and Pollution Research on November 22nd, 2021. See the published version at https://doi.org/10.1007/s11356-02117595-z. 


\section{Environmental Degradation in Somalia}

Abdimalik Ali Warsame*1

Samuel Asumadu SARKODIE ${ }^{2}$

${ }^{1 *}$ Garaad Institute for Social Research and Development Studies, Mogadishu, Somalia

1* Faculty of Economics, SIMAD University, Mogadishu, Somalia

${ }^{2}$ Nord University Business School (HHN). Post Box 1490, 8049 Bodø, Norway

*Email for correspondence: abdimalikali1995@gmail.com

\section{Abstract}

While there are enormous studies on climate change in stable countries, climate policy perspectives from conflict-prone regions including Somalia are limited. This study investigates the asymmetric impact of energy and economic growth on environmental degradation in Somalia-by employing nonlinear autoregressive distributed lag model (NARDL) and causal techniques from 1985 to 2017. We find asymmetric long-term cointegration among the variables, whereas energy consumption and economic growth asymmetrically affect environmental degradation. Besides, the causal inferences reveal unidirectional causality from environmental pollution to positive change in energy consumption. Additionally, we find unidirectional causality from negative shock in economic growth to positive shock in economic growth. Moreover, a bidirectional causality is observed between population growth and negative change in economic growth. A unidirectional causality is confirmed from positive shock in economic growth to population growth-from negative change in economic growth to negative shock in energy consumption-from positive change in economic growth to positive shock in energy consumption - and negative change in energy consumption to population growth. This calls for the implementation of clean energy investment policies, good farming methods, and improved grazing land policies. The adoption of these policies will improve both environmental quality and sustained economic development. 
28 Keywords: Energy, Economic growth, Environmental degradation, NARDL, Somalia

\section{1. Introduction}

30 Energy is a vital source for socio-economic activities by sustaining livelihoods and wellbeing while

31 fostering sustainable development (Owusu and Asumadu, 2016). However, the role of energy-

32 typically fossil fuels - in promoting environmental pollution has raised several global concerns

33 (Sarkodie \& Strezov, 2018). Thus, achieving sustainable economic growth by preserving

34 environmental quality remains topical and timely since the last century. Sustainable development goals

35 (SDGs) of the United Nations (2015-2030 period) have emphasized the importance of achieving

36 economic growth by adopting SDG 8 (decent work and economic growth), but the goal offers a

37 potential tradeoff between sustained economic development and environmental quality. To mitigate

38 greenhouse gas (GHG) emissions and enhance environmental quality while achieving sustained

39 economic growth, the United Nations adopted SDG 7-of ensuring accessible, sustainable, reliable,

40 affordable, and modern energy for all. However, modern energy reduces the double burden of climate

41 change by improving environmental quality, reducing poverty rates, hunger, creating employment

42 opportunities, and promoting economic development (Bhattacharya, Paramati, Ozturk, \&

43 Bhattacharya, 2016; Owusu and Asumadu, 2016; Luqman, Ahmad, \& Bakhsh, 2019).

44 But unfortunately, global fossil fuel consumption outpaces alternative energy sources including clean 45 and renewable energy_contributing $79.67 \%$ of total global energy consumption (World Bank, 2015).

46 Fossil fuel energy consumption enhances economic growth at the cost of environmental quality. On

47 the other hand, economic growth significantly contributes to energy consumption. Accordingly,

48 several studies on energy-growth-environment nexus have verified the energy-led growth

49 hypothesis — attributing sustained economic growth to energy consumption (Kouton, 2019; Akadiri,

50 Bekun, \& Sarkodie, 2019). Cherni \& Essaber Jouini, (2017) and Asumadu-Sarkodie \& Owusu, (2016)

51 confirmed the feedback hypothesis, which posits a mutual causal effect between energy consumption

52 and economic growth. Besides, numerous studies validate the conservative hypothesis, which

53 underscores intensive energy utilization driven by economic development (Bekun, Emir, \& Sarkodie,

54 2019; Ahmed, Shahbaz, Qasim, \& Long, 2014). Likewise, it is also true that economic growth driven

55 by the combustion of energy and industrialization escalate environmental pollution by releasing $\mathrm{CO}_{2}$, 
methane, nitrous oxide emissions and reducing forest areas (Farhani \& Shahbaz, 2014; Sarkodie \&

57 Strezov, 2019; Rafindadi \& Usman, 2019; Sharma \& Kautish, 2020).

58 Somalia has been severely affected by over two decades of civil conflicts and political instabilities.

59 While the country's economic production is an agrarian-based economy with limited economic

60 diversification, half of the country's population is under the poverty line (World Bank, 2018). Despite

61 Somalia is regarded as one of the least energy-consuming nations in the world, $82 \%$ of the country's

62 total energy consumption consists of traditional biomass including firewood and charcoal (Federal

63 Government of Somalia, 2015). Charcoal is used locally and exported through trade to Gulf

64 cooperation Council countries. Around 80-90\% of Somalia's population utilizes biomass fuels such as

65 firewood and charcoals for cooking. Commiphora and acacia are two of the most deforested trees

66 converted into charcoal. Moreover, Somalia consumes 4 million tons of charcoal per year as energy

67 (Federal Government of Somalia, 2015; African Development Bank, 2015). However, this erodes the

68 few remaining forests due to lack of government protection, leading to loss of biodiversity. Hence,

69 affect environmental quality which ultimately increases temperature and induces climate change. It is

70 argued that climate change consequences are already present in Somalia because of recurrent droughts

71 and flash floods. Moreover, Somalia is counted as one of the most vulnerable countries exposed to

72 climatic variabilities (Wheeler, 2011). As a result, increasing temperatures, droughts, and flash floods

73 have been noted in Somalia's national development plan as major climatic risks (Federal Government

74 of Somalia, 2013).

75 Furthermore, environmental degradation in Somalia is evidenced by the increasing rate of 76 deforestation - which is measured as one of the main sources of environmental degradation.

77 According to Figure 1, the deforestation rate has been rising marginally from 1961 to 2001, but in

78 2002, the rate of deforestation skyrocketed from 1.66\% in 2001 to 1.91\% in 2002. The highest rate of

79 deforestation is recorded in 2005 (2.15\%). But in subsequent years, the rate of forest clearing declined,

80 despite it is higher than the rates recorded in the last century. Thus, this is attributed to the country's

81 dependence on biomass fossil fuel energy consumption, poor agricultural practices, and overgrazing

82 land. Moreover, charcoal trade export is another factor that results in widespread deforestation.

83 Consequently, removing forest trees enhances soil erosions, desertification, and exposure to natural

84 hazards including extreme floods and droughts - which ultimately inhibits environmental quality.

85 Moreover, environmental degradation—as a result of deforestation—releases carbon dioxide, leading 


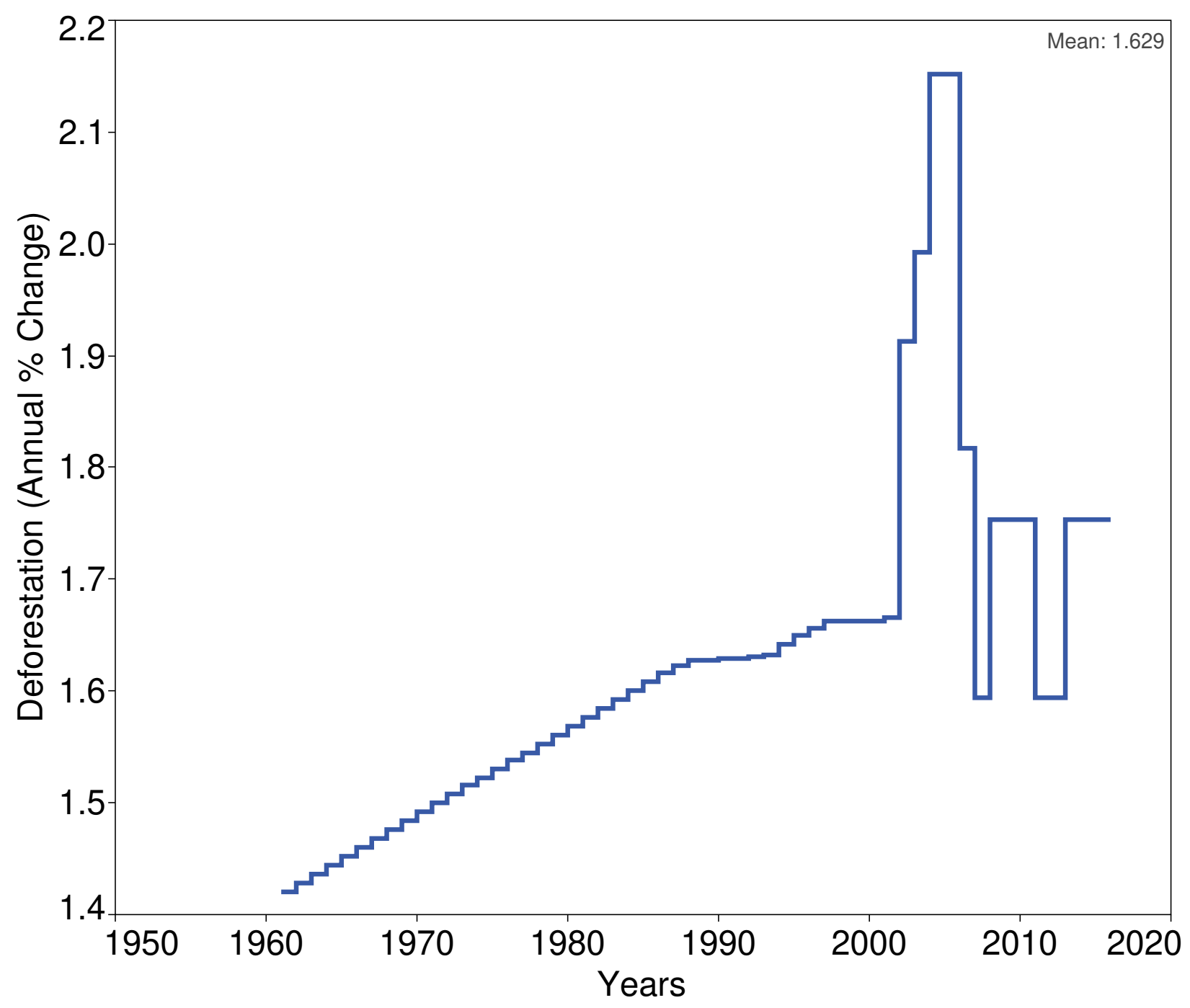

Figure 1. Annual \% Change in Deforestation. Data Source: World Bank

92 Because environmental quality is affected by energy and economic growth, existing literature employs

93 several indicators for measuring environmental pollution including, inter alia, $\mathrm{CO}_{2}$, methane, nitroxide

94 emissions, ecological footprint, and deforestation. Carbon dioxide is the largest contributor of 95 greenhouse gas (GHG) emissions, which is responsible for $72 \%$ of total GHG (Olivier \& Peters, 96 2019), justifying why most existing literature adopted $\mathrm{CO}_{2}$ emissions as proxy for environmental 
pollution (Bölük \& Mert, 2014; Farhani \& Shahbaz, 2014; Shafiei \& Salim, 2014; Jamel \& Abdelkader,

98 2016; Ssali, Du, Mensah, \& Hongo, 2019; Nathaniel \& Iheonu, 2019).

In a panel study of 16 European countries, it is reported that the impact of energy consumption on $\mathrm{CO}_{2}$ emissions encompasses fossil fuel and renewable energy, and economic growth (Bölük \& Mert, 101 2014). Both sources of energy inhibit environmental quality, whereas economic growth reduces $\mathrm{CO}_{2}$, 102 and squared term of economic growth rises $\mathrm{CO}_{2}$ emissions-confirming the invalidity of EKC 103 hypothesis. Similarly, the impact of renewable, non-renewable electricity consumption and economic 104 growth on $\mathrm{CO}_{2}$ emissions is reported in 10 MENA countries (Farhani \& Shahbaz, 2014). Renewable, 105 non-renewable electricity consumption, and economic growth are reported to enhance $\mathrm{CO}_{2}$ emissions, 106 while the squared term of economic growth mitigates $\mathrm{CO}_{2}$ emissions - thus, validating the EKC 107 hypothesis. Again, both fossil fuel energy utilization and economic growth are found to escalate 108 environmental pollution in OECD countries (Shafiei \& Salim, 2014).

109 In a follow-up study, energy and economic growth are reported to have significant positive influence 110 on $\mathrm{CO}_{2}$ emissions in 8 Asian countries (Jamel \& Abdelkader, 2016). A recent study on the nexus 111 between energy, $\mathrm{CO}_{2}$ emissions, foreign direct investment, and economic growth found energy and 112 growth increase $\mathrm{CO}_{2}$ emissions in 6 Sub-Saharan African countries (Ssali, Du, Mensah, \& Hongo, 113 2019). But the squared term of economic growth reduces $\mathrm{CO}_{2}$ emissions, validating the EKC 114 hypothesis. The impact of renewable and fossil energy on $\mathrm{CO}_{2}$ emissions abatement was assessed in 11519 African countries (Nathaniel \& Iheonu, 2019). Renewable energy was found to reduce $\mathrm{CO}_{2}$ 116 emissions whereas fossil fuels undermine environmental quality by increasing $\mathrm{CO}_{2}$ emissions. Energy 117 and economic growth were reported to have positive and negative effects on $\mathrm{CO}_{2}$ emissions in South 118 Africa (Bekun, Emir, \& Sarkodie, 2019). The study also observed a unidirectional causality from energy 119 use to economic growth and environmental pollution. This finding is consistent with the studies of 120 Mohiuddin et al., (2016) who revealed energy use unidirectionally causes economic growth and 121 environmental pollution.

122 Despite the extensive studies on $\mathrm{CO}_{2}$, energy consumption, and economic growth nexus, it is worth 123 noting that developing and least developed countries contribute a tiny fraction of the global $\mathrm{CO}_{2}$ 124 emissions. For instance, the African continent contributes 2-3\% of the global $\mathrm{CO}_{2}$ emissions (United 125 Nations, 2006). Though industrialized-driven $\mathrm{CO}_{2}$ emissions is not an issue in least-developed 126 countries such as Somalia, however, other options contribute to environmental pollution including 
127 deforestation, ecological footprint, and others. Nevertheless, few studies have systematically employed 128 environmental degradation indicators-other than $\mathrm{CO}_{2}$ emissions such as deforestation, ecological 129 footprint, methane, and nitrous dioxide emissions. Some notable studies include Ref. (Baz et al., 2020; 130 Och, 2017; Esmaeili \& Nasrnia, 2014; Ahmed, Shahbaz, Qasim, \& Long, 2014; Zambrano131 Monserrate, Carvajal-Lara, Urgilés-Sanchez, \& Ruano, 2018; Chiu, 2012; Waluyo \& Terawaki, 2016).

132 The asymmetric impact of energy and economic growth on ecological footprint revealed a positive 133 and negative shock in energy consumption enhances environmental quality — whereas a positive shock 134 in economic growth hampers environmental quality and a negative shock in economic growth tends 135 to increase environmental quality (Baz et al., 2020). Moreover, Akadiri, Bekun, \& Sarkodie, (2019) 136 examined the nexus between energy, economic growth, and ecological footprint in South Africa by 137 utilizing an ARDL methodology. The study found energy consumption hampers environmental 138 quality, whereas an increase in economic growth enhances environmental quality. Moreover, they 139 reported environmental pollution granger causes economic growth whereas energy causes economic 140 growth and environmental pollution. The study reported bidirectional causation between a positive 141 change in environmental quality and energy consumption. In contrast, economic growth undermines 142 environmental quality in Mongolia, whereas the squared term of economic growth enhances 143 environmental quality-validating the EKC hypothesis (Och, 2017). Besides, the study found 144 bidirectional causation between environmental pollution and economic growth.

145 Furthermore, economic growth has positive long-term effects on deforestation in Iran, whereas the 146 squared term of income inhibits deforestation (Esmaeili \& Nasrnia, 2014). Hence, the result confirmed 147 the existence of an EKC in Iran. Likewise, Ahmed, Shahbaz, Qasim, \& Long, (2014) validated the 148 EKC hypothesis by utilizing deforestation as environmental pollution indicator, and found both 149 energy consumption and economic growth undermine deforestation. Moreover, energy and economic 150 growth are observed to cause environmental pollution whereas bidirectional causality is found 151 between energy and economic growth. Also, Zambrano-Monserrate, Carvajal-Lara, Urgilés-Sanchez, 152 \& Ruano, (2018) analyzed the EKC hypothesis in 5 European countries using deforestation as 153 measurement for environmental pollution. The results validated the EKC hypothesis-where 154 economic growth increases environmental pollution whereas squared term of economic growth 155 reduces environmental pollution in 4 of 5 countries investigated. Besides, a unidirectional causality is 156 observed from economic growth to deforestation. The validity of the hypothesis is further confirmed 
by Ref. (Chiu, 2012; Waluyo \& Terawaki, 2016), who employed deforestation as indicator for 158 environmental degradation.

159 Notwithstanding, there is scanty literature that ascertains deforestation-energy-growth nexus in Africa, 160 specifically in Somalia. Thus, it is timely to ascertain the impact of energy and economic growth on 161 environmental degradation in conflict-prone countries including Somalia. This study contributes to 162 the literature in several ways - first, to the best of our knowledge, this is the first study conducted in 163 Somalia to address the impact of energy and economic development on environmental degradation.

164 Second, extant literature fails to consider deforestation as indicator for environmental pollution in 165 least developed countries dependent on wood fuel. Third, majority of previous studies investigated 166 energy-growth-environment nexus symmetrically, even though the nexus could be nonlinear due to 167 financial, socioeconomic and political changes that exert nonlinear effect on energy and economic 168 growth. Thus, this study examines the asymmetric impact of energy and economic development on 169 environmental degradation in Somalia. We employ recent nonlinear ARDL econometric methodology 170 by utilizing deforestation as indicator for environmental pollution.

171 The remaining sections of the study are structured as follows: Chapter 2 presents data sources, 172 descriptions and methodology, Chapter 3 reports empirical results and discussion and Chapter 4 173 concludes the study and suggests policy recommendations to concerned policy makers.

\section{Data and Methodology}

\subsection{Data source and Description}

177 Energy is crucial for socio-economic development, however, the dependence on fossil fuels escalates 178 GHG emissions - which leads to climate change_affecting global temperature. Thus, this study 179 ascertains the impact of energy consumption and economic growth on environmental degradation in 180 Somalia by using time series data spanning 1985-2017. The selection of data period is limited to data 181 availability. The data is sourced from World Bank, Organization of Islamic Countries (OIC) database 182 and our world in data. We employed several variables including environmental pollution, energy 183 consumption, economic growth and population growth. All variables were converted into natural 184 logarithm to reduce heteroskedasticity. To date, various indicators have been introduced to measure environmental pollution. Previous literature employed $\mathrm{CO}_{2}$ emissions as indicator for environmental 
186 pollution, however, we utilize deforestation as indicator for environmental degradation. Deforestation

187 is proxied as arable land (hectares). In Somalia, deforestation is the main contributor of environmental 188 degradation. Besides, energy consumption is measured in energy use (kg oil equivalent per capita).

189 Real GDP per capita is used as a proxy of economic growth/income. It is argued that climate change

190 is related to the consequences of human activities. Therefore, to account for this, we include

191 population growth as a control variable in our model to account for the effect of human activities on

192 environmental degradation.

\subsection{Econometric Methodology}

194 We apply NARDL framework methodology to estimate the short- and long-run effects of energy, 195 economic growth and environmental degradation nexus. One of the shortfalls of linear ARDL and 196 other previous cointegration methods is that they ignore the asymmetric relationship between the 197 investigated variables. Therefore, Shin et al., (2014) proposed NARDL technique which considers the 198 nonlinearity of the variables. Hence, it is advanced method of the ARDL cointegration method. The 199 main idea behind NARDL is to capture the effects of hidden and unpredicted events such as economic

200 crises, political and social changes, which cannot be captured in linear models. Thus, this technique is 201 applicable to the context of environment-energy-growth nexus in Somalia. Unlike other cointegration 202 methods such as Johansen cointegration and Engle \& Granger cointegration methods, NARDL is 203 advantageous in estimating variables integrated at level I (0), first difference I (1) or combination of 204 both (Sarkodie and Adams, 2020). Moreover, NARDL framework is suitable in dealing with 205 convergence issues, which is better than the conventional cointegration methods. Another advantage 206 of NARDL is that it avoids the problem of multicollinearity by using an effective automatic lag 207 selection criterion. The NARDL model utilized herein can be expressed as:

$208 z_{t}=z_{0}+z_{t}^{+}+z_{t}^{-}$

209 Where $z_{t}^{+}$and $z_{t}^{-}$indicate the partial sum of positive and negative shocks occur in $z_{t}$ :

$z_{t}^{+}=\sum_{j=1}^{t} \Delta z_{j}^{+}=\sum_{j=1}^{t} \max \left(\Delta x_{j}, 0\right)$

$z_{t}^{-}=\sum_{j=1}^{t} \Delta z_{j}^{-}=\sum_{j=1}^{t} \min \left(\Delta x_{j}, 0\right)$

212 The long-run asymmetric cointegration of the variables can be specified as:

$213 y_{t}=\alpha_{0}+\beta^{+} z_{t}^{+}+\beta^{-} z_{t}^{-}+\mu_{t}$ 
214 Where $\alpha_{0}$ is the intercept, $\beta^{+}$and $\beta^{-}$represent the long-run coefficient elasticities of the explanatory 215 variables. $\beta^{+}$is intended to capture the long-term positive shock of variable $z$ on $y$, whereas $\beta^{-}$ 216 captures the long-term negative shock of $z$ on $y$. According to Shin et al., (2014), utilizing equation 217 (3) can specify the NARDL framework, which represents the asymmetric error correction term 218 expressed as:

$\Delta y_{t}=\alpha_{0}+\Delta y_{t-1}+\delta^{+} z_{t-1}^{+}+\delta^{-} z_{t-1}^{-}+\sum_{j=1}^{p-1} \alpha_{j} \Delta y_{t-j}+\sum_{j=0}^{q-1} \beta_{j}^{+} \Delta z_{t-j}^{+}+\sum_{j=0}^{q-1} \beta_{j}^{-} \Delta z_{t-j}^{-}+\mu_{t}$

221 Where $\mathrm{y}$ is the regressed variable, $\mathrm{x}$ is the explanatory variable, $\mathrm{p}$ and $\mathrm{q}$ is the optimal lag length of the 222 dependent and independent variables, respectively, $\delta^{+}$and $\delta^{-}$is the asymmetric long-term 223 coefficients, $\beta_{j}^{+}$and $\beta_{j}^{-}$represent the short-term dynamic effect of coefficient elasticities and $\mu_{t}$ is 224 the error term.

225 We apply Wald-F test to ascertain the validity of long-run asymmetric cointegration among the 226 investigated variables. Moreover, the study utilizes Broock, Scheinkman, Dechert, \& LeBaron, (1996) 227 nonlinearity of BDS test to examine nonlinearity of the series. The long-term null hypothesis is set as: $228 \delta^{+}=\delta^{-}$(no asymmetric cointegration) against the alternative $\delta^{+} \neq \delta^{-}$(there is asymmetric 229 cointegration). If the Wald F-statistics is greater than the upper bound critical values, the null 230 hypothesis of no asymmetric long-term cointegration is rejected. Thus, validating the existence of 231 asymmetric long-term cointegration among the variables. If the critical value is above the Wald F232 statistics, we fail to refute the null hypothesis of no asymmetric long-term cointegration. Moreover, if 233 the Wald F-statistics falls between the two critical values, the decision becomes inconclusive.

234 The final and general model of our investigated variables - $\ln D E F O, \ln R G D P C, \ln E C$ and $\ln P G$ - in 235 the NARDL framework can be expressed as (Bekun et al., 2019; Sarkodie and Adams, 2020; and 236 Ahmed, Shahbaz, Qasim, \& Long, 2014): $\Delta \ln D E F O_{t}=\alpha_{0}+\Delta \ln D E F O_{t-1}+\delta_{1}^{+} \ln E C_{t-1}^{+} \delta_{1}^{-} \ln E C_{t-1}^{-}+\delta_{2}^{+} \ln R G D P C_{t-1}^{+}+\delta_{2}^{-} \ln R G D P C_{t-1}^{-}$

$$
\begin{aligned}
& +\delta_{3} \ln P G_{t-1}+\sum_{j=1}^{p-1} \beta_{j} \Delta \ln D E F O_{t-j}+\sum_{j=0}^{q-1} \beta_{1 j}^{+} \Delta \ln E C_{t-j}^{+}+\sum_{j=0}^{q-1} \beta_{1 j}^{-} \Delta \ln E C_{t-j}^{-} \\
& +\sum_{j=0}^{q-1} \beta_{1 j}^{+} \Delta \ln R G D P C_{t-j}^{+}+\sum_{j=0}^{q-1} \beta_{1 j}^{-} \Delta \ln R G D P C_{t-j}^{-}+\sum_{j=1}^{q-1} \beta_{j} \Delta \ln P G_{t-j}+\varepsilon_{t}
\end{aligned}
$$


Where $\ln \mathrm{DEFO}$ denotes $\log$ of deforestation proxied for environmental degradation, $\operatorname{lnEC}$ represents energy consumption, lnRGDPC signifies real GDP per capita, p \& q denote the optimal lag length of

242 dependent and explanatory variables.

\section{Empirical Results and Discussion}

\subsection{Descriptive Statistics}

Descriptive statistics presents the characteristics of the data. Table 1 outlines the summary statistics of the variables including mean, median, standard deviation and among others. Deforestation and energy consumption have the highest average values of 13.8 and 5.8, respectively. Whilst population growth has the lowest average value (1.15). In the same vein, deforestation, energy consumption and real GDP have maximum values of 14.1, 6.7 and 5, respectively. But population growth has the lowest mean, median, maximum and minimum values. On the contrary, population growth has the highest standard deviation (0.38) compared to all other variables-indicating the values of population growth are far from its average. Besides, Table 1 also presents the correlation among the interested variables. Energy consumption and real GDP per capita have negative correlation with deforestation whereas positive correlation is found between deforestation and population growth. A positive relationship is observed between real GDP and energy consumption whereas there exists negative correlation between real GDP and population growth. In addition, population growth is negatively correlated with energy consumption and real GDP per capita, whereas a positive correlation is established between population and deforestation.

Table 1: Descriptive Statistics

$\begin{array}{cccc}\ln D E F O & \operatorname{lnEC} & \operatorname{lnRGDPC} & \ln P G \\ 13.8871 & 5.853653 & 4.649785 & 1.158153 \\ 13.8576 & 5.745077 & 4.523417 & 1.317473 \\ 14.1156 & 6.778529 & 5.064555 & 1.567599 \\ 13.8155 & 5.496287 & 4.498364 & 0.247130 \\ 0.0795 & 0.349871 & 0.211245 & 0.383316\end{array}$


273 Testing the stationarity of time series data is a requirement of the NARDL technique and essential to

274 control for spurious regression, hence, producing unbiased results. To test the unit root of our 275 interested variables and prevent model misspecification and biased inferences, we utilized Augmented 276 Dickey Fuller (ADF) and Philips-Perron (PP) tests. The results of the unit root test presented in Table 2772 highlight that all variables contain unit root problems, viz. level I (0), except population growth 278 which is stationary in ADF. In contrast, all variables are stationary at first difference I (1). The ADF and PP tests are inadequate to detect the presence of structural break dates, therefore, we used Zivot \& Andrews, (1992) unit root test to check for structural break date of the series to avoid misspecified model estimation and incorrect inferences. However, the structural break unit root test presented in

282 Table 2 confirm that all series are integrated at first difference I (1). Hence, we proceeded to estimate 283 the nonlinear ARDL model.

\subsection{Unit Root Tests}

Table 2. Unit Root Tests

ADF

PP

$\underline{\mathrm{ZA}}$

\section{Variable}

T-statistics

T-statistics

Structural Break Unit Root Test

lnDEFO $\quad-2.9883$

$-2.1945$

T-statistics

Time Break

292

$\operatorname{lnRGDPC} \quad-3.1825$

$-1.1392^{* * *}$

$-5.3718(1)^{* *}$

2002

292

293

$\ln \mathrm{EC}$

$-2.2325$

$-2.1970$

$-8.7213(0) * * *$

1994

$\ln P G \quad-35.4002 * * *$

$-2.2718$

$-4.6391(4)$

2012

$\Delta \ln \mathrm{DEFO} \quad-4.3080 * * *$

$-5.9454 * * *$

$-9.2904 * * *(4)$

1996

$295 \Delta \ln R G D P C-2.7325$

$-5.9296 * * *$

$-6.8032(1) * * *$

2006

$296 \quad \Delta \ln \mathrm{EC} \quad-5.3904 * * *$

$-5.3908^{* * *}$

$-17.9212(0) * * *$

1996

297

$\Delta \ln P G \quad-1.6992^{* * *}$

$-2.9030$

$-7.2244 * * *(0)$

1993

Notes: $\Delta$ denotes first difference. ADF and PP stand for Augmented Dickey-Fuller and Philips Perron tests respectively. The T-statistics reported are the intercept and trend. ZA stands for Zivot-Andrews. 
301 The study employed BDS test to check the nonlinearity of the series presented in Table 3. Broock, 302 Scheinkman, Dechert, \& LeBaron, (1996) postulated this method to detect and test the predicted 303 residuals of time series model which have been converted into identically scattered errors. The null 304 hypothesis $\left(\mathrm{H}_{0}\right)$ is formulated as: the series are normally and identically distributed—which implies 305 that the data is dependent (linear), whereas the alternative hypothesis $\left(\mathrm{H}_{0}\right)$ expresses a violation of 306 normal and identical distribution-implying that the series are nonlinear. Thus, the z-statistics of all 307 series indicate statistical significance-leading to the rejection of null hypothesis and failure to reject 308 the alternative hypothesis of non-normal distribution of the series. Hence, this confirms that the series 309 are non-linear, and further verifies the suitability of NARDL model in this study (Energy-growth310 environment nexus).

Table 3: Nonlinearity of BDS test

312

\begin{tabular}{llll}
\hline $\ln D E F O$ & $\ln E C$ & $\ln R G D P C$
\end{tabular}

313 Dimension

314

315

316

$$
\text { Dimension }
$$

14

BDS

BDS

z-Stat BDS z-Stat

0.1244

6.0705

0.2035

10.2346

BDS z-Stat

BDS z-Stat

2

0.2112

6.2734

$0.34651 \quad 10.6671$

0.20199

12.3083

0.1501

8.8449

$4 \quad 0.2605$

$\begin{array}{lll}6.2782 & 0.4441 & 11.1575\end{array}$

0.34253

12.9243

0.2415

8.7217

$0.43907 \quad 13.6811$

0.2953

8.7172

$\begin{array}{lll}6.2704 & 0.5085 & 11.9049\end{array}$

0.50293

14.7769

0.3280

9.0334

$\begin{array}{lll}6.1575 & 0.5498 & 12.9516\end{array}$

$0.5445 \quad 16.2931$

$0.3447 \quad 9.5668$

The next step after passing through the unit root test is the selection of optimal lag-length. Thus, we employed Stepwise Least Square approach to select the optimal lag-length. Owing to our small sample 322 size, we limited the highest lag number to 2, then, determined the existence of long-run asymmetric 323 cointegration among the variables, and its result is presented in Table 4. We used Wald F-test by 324 comparing it with the critical values, however, the Wald F-statistic (7.5) is above the critical value of 3256.9 at $1 \%$ significance level. Hence, confirming long-run asymmetric cointegration between 326 environmental degradation and the regressors.

Table 4: F-Bounds Cointegration Tests

Model $\quad$ F-statistic Significance $\quad$ Bounds test critical values


$1 \%$

$5 \%$

$10 \%$
I (0)

I (1)

333

334

335

Notes: The critical values are based on Narayan (2005). $K=$ number of explanatory variables.
5.333

6.975

4.965

3.653

4.133
After determining the existence of long-run cointegration among the variables, we estimated the longrun asymmetric elasticities and short-run asymmetric dynamic effect with error correction term (ECT) of the explanatory variable reported in Table 5. The positive shock of energy consumption and economic growth induces positive effects on environmental degradation in the long-run, whereas negative shock of energy consumption and economic growth have no long-run significant effect on environmental degradation in Somalia. Interpretively, 1\% shock increase in energy consumption and economic growth increases environmental degradation in the long-run by $\sim 2.44 \%$ and $7.58 \%$, respectively. However, both energy consumption and economic growth have adverse effect on environmental quality. Moreover, population growth is observed to have insignificant effect on environmental pollution in the long-run. Our findings of positive effect of economic growth and energy consumption on environmental degradation is corroborated studies in Iran (Esmaeili \& Nasrnia, 2014), Pakistan (Ahmed, Shahbaz, Qasim, \& Long, 2015), 6 SSA countries (Ssali, Du, Mensah, \& Hongo, 2019).

The positive effects of energy consumption and economic growth on environmental degradation is not unusual. Energy consumption is the main driver of environmental pollution-higher percentage of Somalia's final energy consumption consists of biomass, viz. charcoal and firewood. Consequently, an increase in energy use depletes forest areas, and leads to soil erosions, releasing atmospheric $\mathrm{CO}_{2}$ emissions-which undermines environmental quality. Moreover, poverty level and dominant rural population comprising $65 \%$ of total population engage in agropastoral and pastoral activities — driving deforestation rate to meet livelihood pressures. Majority of livelihoods depend on fuelwood and charcoal production, which depletes forest reserve and resources-leading to loss of biodiversity. Thus, lack of biomass alternatives due to conflicts and limited investments in clean energy exacerbates environmental quality. 
On the other hand, despite the positive change, energy consumption is regarded determinant of environmental degradation, positive change in economic growth is considered the highest significant driver of environmental pollution, with coefficient of $7.5 \%$. Some of the remarkable explanations for this effect can be attributed to sources of Somalia's economic growth. Somalia is an agrarian based economy comprising crop and livestock production. This sector creates $65 \%$ of employment opportunities, $93 \%$ of the country's export and represents $65 \%$ of the country's GDP (World Bank; 365 FAO, 2018). While crop production and livestock rearing contribute to higher percentage of the world's deforestation. Thus, environmental quality is affecting by poor cultivation practices, loss of vegetation land, overgrazing land, conflicts over natural resources and lack of technical agricultural extension services. Somalia's economic dependence on agriculture sector implies that an increase in economic growth poses long-term environmental cost.

370
Additionally, one striking point is that neither of the negative change in energy consumption nor economic growth enhances environmental quality. Implying that energy efficiency and decarbonized economic development is expected to rise environmental quality. However, such sustainable options are lacking in Somalia, due to limited environmental regulations. Somalia's political instability and lack of good governance for over two decades has consequently affected environmental protection, thus, the adoption of NARDL captured the nonlinear effects. Somalia's forest areas is traded globally by producing and exporting illegal charcoal compared to countries with institutional quality, where such illegal trading is prohibited.

The short-run dynamics and ECT are reported in Table 5. Historical pollution (deforestation) has a positive effect on current environmental pollution by $0.40 \%$. A positive shock in energy consumption has a favorable effect on environmental quality by reducing environmental degradation by $1.79 \%$ in the short-run. Contrary, $1 \%$ increase in negative shock of energy consumption spur environmental pollution by $0.46 \%$ in the short-run. Moreover, a positive shock in economic growth has no significant effect on environmental pollution in the short-run. But 1\% increase in negative shock of economic growth escalates environmental degradation by $0.75 \%$ in the short-run. Despite population growth is insignificant in the long-run, the short-run finds unfavorable effect on environmental quality. 1\% increase in population growth reduces environmental quality by $0.66 \%$ in the short-run. More importantly, Table 5 displays the ECT which denotes the speed of adjustment. The ECT is significant at $1 \%$ level and accompanies a negative coefficient, thus, this confirms the existence of long-run 
389 cointegration among the variables. Any short-run disequilibrium that occurs in environmental

390 degradation is adjusted by the explanatory variables in the long-run by $93 \%$ annually.

391

392

393

394

395

396

397

398

399

400

401

402

403

404

405

406

407

408

409

410

411

412

413

414

415

416

417

418

419

420

421

422

423

424

425

426

427

Table 5. Long-Run and Short-run Coefficient Elasticities

\begin{tabular}{|c|c|}
\hline Variable & Coefficient \\
\hline \multicolumn{2}{|l|}{ Long-Run Coefficient Elasticities } \\
\hline \multirow[t]{2}{*}{$\ln \mathrm{EC}^{+}$} & $2.4454 * * *$ \\
\hline & $(6.4495)$ \\
\hline \multirow[t]{2}{*}{$\operatorname{lnEC^{--}}$} & 0.0308 \\
\hline & $(0.7335)$ \\
\hline \multirow[t]{2}{*}{$\ln \mathrm{RGDPC}^{+}$} & $7.5898^{* * *}$ \\
\hline & $(6.2740)$ \\
\hline \multirow[t]{2}{*}{$\operatorname{lnGDPC} C^{--}$} & -0.0087 \\
\hline & $(-0.1253)$ \\
\hline \multirow[t]{2}{*}{$\ln P G$} & -0.0374 \\
\hline & $(-1.7002)$ \\
\hline
\end{tabular}

Coefficient

Constant $\quad 6.7495^{* * *}$

$(5.8705)$

$\Delta(\ln \mathrm{DEFO}(-1)) \quad 0.4065^{* * *}$

(2.9884)

$-1.7991 * *$

$(-2.4913)$

$0.4680 * * *$

(3.0539)

2.7198

(0.8174)

$\Delta\left(\ln \operatorname{RGDPC}^{+}(-2)\right) \quad 0.7251$

$(1.2174)$

$\begin{array}{ll}\Delta\left(\ln \mathrm{RGDPC}^{--}\right) \quad & 0.7546^{* * *} \\ & (3.0251)\end{array}$

$\Delta\left(\ln R\right.$ DPPC $\left.^{--}(-1)\right) \quad-0.2632$

$(-0.9601)$

$-0.4251^{*}$

$\Delta\left(\ln \operatorname{RGDPC}^{--}(-2)\right)$

$(-1.7854)$

$0.6651^{* *}$

$\Delta(\ln P G)$

(2.1439)

$\Delta(\ln P G(-1)) \quad-1.0735^{*}$ 
$(-2.0479)$

0.3226

(1.2043)

$-0.9380^{* * *}$

$(-5.8774)$

Note: $* * *$ and $* *$ indicates significance at $1 \%$ and $5 \%$ levels, respectively. T-statistic are reported in parenthesis. $\Delta=$ differencing.

For sound, reliable and accurate empirical results, we conducted several diagnostic tests as shown in Table 6. We applied serial correlation, heteroskedasticity, reset test and normality test. More importantly, we tested the model's parameter stability. Nevertheless, no serial correlation, misspecification model (reset test), heteroskedasticity and non-normality problems are detected, implying the findings are reliable for policy formulation. The value of adjusted R-squared (0.60) denotes that energy, economic growth and population growth explain $60 \%$ of variations in environmental degradation. Moreover, CUSUM and CUSUM square tests presented in Figure 2 confirm that the parameters of the study are stable over time.

Table 6: Diagnostic Tests

\begin{tabular}{ll}
\hline LM Test & $\begin{array}{l}0.0857 \\
(0.8489)\end{array}$ \\
& 0.4892 \\
Heteroskedasticity Test & $(0.8013)$ \\
& 3.7737 \\
Normality Test & $(0.1516)$ \\
& 0.0119 \\
Reset Test & $(0.9146)$ \\
& 0.6071 \\
\hline
\end{tabular}



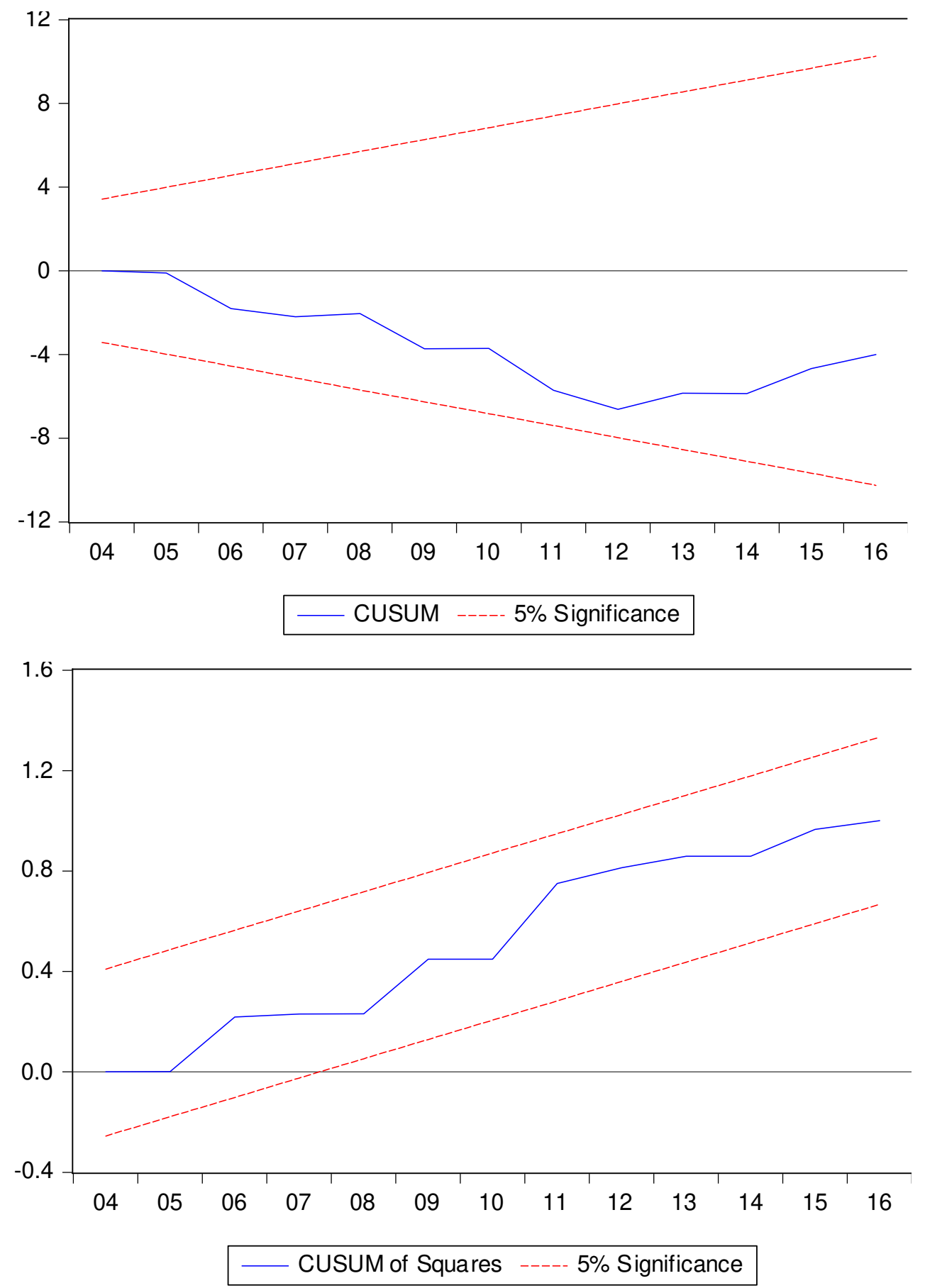

\subsection{Results of Granger Causality}

468 To determine the direction of causation among the investigated variables, we utilized Granger causality 469 test. The result presented in Table 7 reveal unidirectional causation from environmental pollution to 470 positive change in energy consumption, whereas negative change in economic growth causes positive 
471 shock in economic growth. Moreover, bidirectional causality is established between population growth 472 and negative change in economic growth. Additionally, negative change in economic growth is also 473 caused by negative shock in energy consumption which verifies the conservative hypothesis. A 474 unidirectional causality is observed from positive shock in economic growth to population growth. 475 On the other hand, positive change in economic growth unidirectionally granger causes positive shock 476 in energy consumption. Finally, another unidirectional is established from a negative change in energy 477 consumption to population growth.

478
Table 7: Results of Granger Causality Tests

\begin{tabular}{|c|c|c|}
\hline Null Hypothesis: & F-Statisti & Prob. \\
\hline $\mathrm{LRGDPC}^{-} \Rightarrow \mathrm{LDEFO}^{-}$ & 1.0626 & 0.3613 \\
\hline $\mathrm{LDEFO} \Rightarrow \mathrm{LRGDPC}^{-}$ & 0.1215 & 0.8862 \\
\hline $\mathrm{LRGDPC}^{+} \Rightarrow \mathrm{LDEFO}$ & 0.6526 & 0.5297 \\
\hline $\mathrm{LDEFO} \Rightarrow \mathrm{LRGDPC}^{+}$ & 1.4164 & 0.2621 \\
\hline $\ln \mathrm{PG} \Rightarrow \mathrm{LDEFO}$ & 1.2487 & 0.3042 \\
\hline $\ln \mathrm{DEFO} \Rightarrow \ln \mathrm{PG}$ & 0.9381 & 0.4047 \\
\hline $\operatorname{lnEC^{+}} \Rightarrow \ln \mathrm{DEFO}$ & 0.0725 & 0.9303 \\
\hline $\operatorname{lnDEFO} \Rightarrow \operatorname{lnEC^{+}}$ & 4.2353 & $0.0266 * *$ \\
\hline 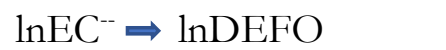 & 0.2471 & 0.7830 \\
\hline $\ln \mathrm{DEFO} \Rightarrow \ln \mathrm{EC}^{--}$ & 0.0323 & 0.9683 \\
\hline $\ln \mathrm{RGDPC}^{+} \Rightarrow \ln \mathrm{RGDPC}^{--}$ & 1.1055 & 0.3467 \\
\hline $\ln \mathrm{RGDPC}^{--} \Rightarrow \ln \mathrm{RGDPC}^{+}$ & 5.0725 & $0.0142 * *$ \\
\hline $\ln \mathrm{PG} \Rightarrow \ln \mathrm{RGDPC}^{--}$ & 14.9304 & 5.E-05*** \\
\hline $\ln \mathrm{RGDPC}^{-} \Rightarrow \ln \mathrm{PG}$ & 25.9674 & 8.E-07*** \\
\hline $\mathrm{LEC}^{+} \Rightarrow \mathrm{LRGDPC}^{--}$ & 0.6667 & 0.5223 \\
\hline $\mathrm{LRGDPC}^{--} \Rightarrow \ln \mathrm{EC}^{+}$ & 1.1224 & 0.3414 \\
\hline 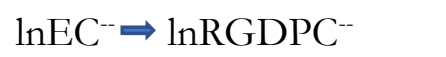 & 10.5826 & $0.0005^{* * *}$ \\
\hline $\ln \mathrm{RGDPC}^{-} \Rightarrow \mathrm{LEC}^{--}$ & 0.26341 & 0.7705 \\
\hline $\ln \mathrm{PG} \Rightarrow \ln \mathrm{RGDPC}^{+}$ & 1.9635 & 0.1614 \\
\hline $\ln \mathrm{RGDPC}^{+} \Rightarrow \ln \mathrm{PG}$ & 6.51176 & $0.0053 * * *$ \\
\hline $\operatorname{lnEC^{+}} \Rightarrow \ln \mathrm{RGDPC}^{+}$ & 1.0492 & 0.3651 \\
\hline $\ln \mathrm{RGDPC}^{+} \Rightarrow \ln \mathrm{EC}^{+}$ & 4.8494 & $0.0166^{* *}$ \\
\hline $\mathrm{LEC}^{--} \Rightarrow \mathrm{LRGDPC}^{+}$ & 0.8418 & 0.4428 \\
\hline
\end{tabular}




$\begin{array}{lll}\mathrm{LRGDPC}^{+} \Rightarrow \mathrm{LEC}^{--} & 1.4990 & 0.2428 \\ \ln \mathrm{EC}^{+} \Rightarrow \ln \mathrm{PG} & 2.5406 & 0.0990^{*} \\ \ln \mathrm{PG} \Rightarrow \mathrm{LEC}^{+} & 0.2798 & 0.7583 \\ \ln \mathrm{EC}-\Rightarrow \mathrm{LPG} & 48.6573 & 2 . \mathrm{E}-09^{* * *} \\ \ln \mathrm{PG} \Rightarrow \mathrm{LEC}^{--} & 0.5739 & 0.5706 \\ \ln \mathrm{EC}^{--} \Rightarrow \operatorname{lnEC^{+}} & 0.5267 & 0.5970 \\ \ln \mathrm{EC}^{+} \Rightarrow \ln \mathrm{EC}^{--} & 1.9318 & 0.1659\end{array}$

Notes: $\Rightarrow$ indicates the null hypothesis that variable " $\mathrm{x}$ " does not granger cause variable “y”, ***,**,* represent statistical significance at 1, 5, 10\% levels.

\section{Conclusion and Policy Implications}

Sustainable development goal 7 and 8 outline affordable and clean energy, and decent work and economic growth, respectively. However, nonrenewable energy and economic growth seem to undermine environmental quality. This study assessed asymmetric impact of energy consumption and economic growth on environmental degradation in Somalia. The study employed a recent econometric methodology of NARDL model. Hence, this study revealed that positive shocks of energy consumption and economic growth degrade environmental quality in the long-run, whilst negative shock of energy consumption and economic growth is statistically insignificant in the long-term. Also, population growth has no significant influence on environmental degradation in the long-term. In the short-term, positive change in energy consumption enhances environmental quality in the short-run, whereas negative shock in energy consumption and economic growth undermines environmental quality, but positive change in economic growth is statistically insignificant in the short-term. Moreover, population growth significantly inhibits environmental quality in the short-term.

Besides, Granger causality is used to check the directional causation among the investigated variables. A unidirectional causality is established from environmental pollution to positive change in energy consumption, and from negative shock in economic growth to positive shock in economic growth. Moreover, bidirectional causality is found between population growth and negative change in economic growth. A unidirectional causality is found from positive shock in economic growth to population growth-from negative change in economic growth to negative shock in energy consumption. On the other hand, positive change in economic growth unidirectionally granger causes 
532 positive shock in energy consumption. Finally, another unidirectional is found from a negative change

533 in energy consumption to population growth.

534 This study suggests several policy implications based on the empirical findings. First, reducing biomass

535 energy consumption would contribute to environmental quality. Hence, policymakers could

536 implement policies by encouraging investments in renewable and clean energy production such as

537 solar, wind, hydroelectric power, and among others. Thus, this will not only improve environmental

538 quality but also enhances economic growth. Implementing energy conservative policies will not hurt

539 economic growth. Moreover, raising awareness towards adverse effect of forest depletions would help

540 decline deforestation, which ultimately inhibits environmental pollution. Since Somalia's GDP is

541 mainly based on agriculture production, policymakers could implement good agricultural cultivation

542 methods, technologies, and improved grazing land policies for livestock will lead to sustainable

543 economic growth and enhance environmental quality while reducing inefficient farming expansion

544 and overgrazing.

545

546

547 The datasets used and/or analyzed during the current study are available from the corresponding

548 author on reasonable request.

549 Compliance with ethical standards

550 Ethical approval

551 Not applicable.

552 Competing interests

553 The authors declare that they have no conflicts of interest.

554 Consent to participate

555 Not applicable.

556 Consent to publish

557 Not applicable.

558 Funding section

559 The author received no financial support for the research, authorship, and/or publication of this

560 article.

561 Credit Author Statement.

562 Abdimalik Ali Warsame: Conceptualization, methodology, data collection and analyzing, writing;

563 original draft. 
Samuel Asumadu Sarkodie: Reviewing and editing.

\section{Reference}

Ahmed, K., Shahbaz, M., Qasim, A., \& Long, W. (2015). The linkages between deforestation, energy and growth for environmental degradation in Pakistan. Ecological Indicators, 49(2014), 95-103. https://doi.org/10.1016/j.ecolind.2014.09.040

Akadiri, S. Saint, Bekun, F. V., \& Sarkodie, S. A. (2019). Contemporaneous interaction between energy consumption, economic growth and environmental sustainability in South Africa: What drives what? Science of the Total Environment, 686, 468-475. https://doi.org/10.1016/j.scitotenv.2019.05.421

Asumadu-Sarkodie, S., \& Owusu, P. A. (2016). Carbon dioxide emissions, GDP, energy use, and population growth: a multivariate and causality analysis for Ghana, 1971-2013. Environmental Science and Pollution Research, 23(13), 13508-13520. https://doi.org/10.1007/s11356-016-6511-x

Baz, K., Xu, D., Ali, H., Ali, I., Khan, I., Khan, M. M., \& Cheng, J. (2020). Asymmetric impact of energy consumption and economic growth on ecological footprint: Using asymmetric and nonlinear approach. Science of the Total Environment, 718, 137364. https://doi.org/10.1016/j.scitotenv.2020.137364

Bekun, F. V., Emir, F., \& Sarkodie, S. A. (2019). Another look at the relationship between energy consumption, carbon dioxide emissions, and economic growth in South Africa. Science of the Total Environment, 655, 759-765. https://doi.org/10.1016/j.scitotenv.2018.11.271

Bhattacharya, M., Paramati, S. R., Ozturk, I., \& Bhattacharya, S. (2016). The effect of renewable energy consumption on economic growth: Evidence from top 38 countries. Applied Energy, 162, 733-741. https://doi.org/10.1016/j.apenergy.2015.10.104

Bölük, G., \& Mert, M. (2014). Fossil \& renewable energy consumption, GHGs (greenhouse gases) and economic growth: Evidence from a panel of EU (European Union) countries. Energy, 74(C), 439-446. https://doi.org/10.1016/j.energy.2014.07.008

Broock, W. A., Scheinkman, J. A., Dechert, W. D., \& LeBaron, B. (1996). A test for independence based 
on the correlation dimension. Econometric Reviews (Vol. 15). https://doi.org/10.1080/07474939608800353

Cherni, A., \& Essaber Jouini, S. (2017). An ARDL approach to the CO2 emissions, renewable energy and economic growth nexus: Tunisian evidence. International Journal of Hydrogen Energy, 42(48), 29056-29066. https://doi.org/10.1016/j.ijhydene.2017.08.072

Chiu, Y. Bin. (2012). Deforestation and the Environmental Kuznets Curve in Developing Countries: A Panel Smooth Transition Regression Approach. Canadian Journal of Agricultural Economics, 60(2), 177-194. https://doi.org/10.1111/j.1744-7976.2012.01251.x

Esmaeili, A., \& Nasrnia, F. (2014). Deforestation and the Environmental Kuznets Curve in Iran. Small-Scale Forestry, 13(3), 397-406. https://doi.org/10.1007/s11842-014-9261-y

Farhani, S., \& Shahbaz, M. (2014). What role of renewable and non-renewable electricity consumption and output is needed to initially mitigate CO2 emissions in MENA region? Renewable and Sustainable Energy Reviews, 40, 80-90. https://doi.org/10.1016/j.rser.2014.07.170

Federal Government of Somalia. (2013). Somalia National Adaptation Programme of Action to Climate Change.

Federal Government of Somalia. (2015). SOMALIA'S INTENDED NATIONALLY DETERMINED CONTRIBUTIONS (INDCS).

Jamel, L., \& Abdelkader, D. (2016). Do energy consumption and economic growth lead to environmental degradation? Evidence from Asian economies. Cogent Economics and Finance, 4(1). https://doi.org/10.1080/23322039.2016.1170653

Kouton, J. (2019). The asymmetric linkage between energy use and economic growth in selected African countries: Evidence from a nonlinear panel autoregressive distributed lag model. Energy Economics, 83, 475-490. https://doi.org/10.1016/j.eneco.2019.08.006

Luqman, M., Ahmad, N., \& Bakhsh, K. (2019). Nuclear energy, renewable energy and economic growth in Pakistan: Evidence from non-linear autoregressive distributed lag model. Renewable Energy, 139, 1299-1309. https://doi.org/10.1016/j.renene.2019.03.008

Magazzino, C., Mutascu, M., Sarkodie, S. A., Adedoyin, F. F., \& Owusu, P. A. (2021). Heterogeneous effects of temperature and emissions on economic productivity across climate 
regimes. Science of the Total Environment, 775, 145893. doi:https://doi.org/10.1016/j.scitotenv.2021.145893

Mohiuddin, O., Asumadu-Sarkodie, S., \& Obaidullah, M. (2016). The relationship between carbon dioxide emissions, energy consumption, and GDP: A recent evidence from Pakistan. Cogent Engineering, 3(1), 1-16. https://doi.org/10.1080/23311916.2016.1210491

Nathaniel, S. P., \& Iheonu, C. O. (2019). Carbon dioxide abatement in Africa: The role of renewable and non-renewable energy consumption. Science of the Total Environment, 679, 337-345. https://doi.org/10.1016/j.scitotenv.2019.05.011

Owusu, P. A., \& Asumadu, S. S. (2016). A review of renewable energy sources, sustainability issues and climate change mitigation. Cogent Engineering, 3(1), 1167990. https://doi.org/10.1080/23311916.2016.1167990

Och, M. (2017). Empirical investigation of the environmental kuznets curve hypothesis for nitrous oxide emissions for Mongolia. International Journal of Energy Economics and Policy, 7(1), 117-128.

Olivier, J. G. J., \& Peters, J. A. H. W. (2019). Trends in Global CO2 and Total Greenhouse Gas Emissions: Report. PBL Netherlands Environmental Assessment Agency. Retrieved from www.pbl.nl/en.\%0Ahttps://www.pbl.nl/sites/default/files/downloads/pbl-2020-trends-inglobal-\%0Awww.pbl.nl/en.

Sarkodie, S. A., \& Adams, S. (2020). Electricity access and income inequality in South Africa: evidence from Bayesian and NARDL analyses. Energy Strategy Reviews, 29, 100480.

Sarkodie, S. A., \& Strezov, V. (2018). Assessment of contribution of Australia's energy production to CO2 emissions and environmental degradation using statistical dynamic approach. Science of the Total Environment, 639, 888-899.

Sarkodie, S. A., \& Strezov, V. (2019). Effect of foreign direct investments, economic development and energy consumption on greenhouse gas emissions in developing countries. Science of the Total Environment, 646, 862-871. https://doi.org/10.1016/j.scitotenv.2018.07.365

Shafiei, S., \& Salim, R. A. (2014). Non-renewable and renewable energy consumption and CO2 emissions in OECD countries: A comparative analysis. Energy Policy, 66, 547-556. https://doi.org/10.1016/j.enpol.2013.10.064 
Sharma, R., \& Kautish, P. (2020). Examining the nonlinear impact of coal and oil-based electricity production on CO2 emissions in India. Electricity Journal, 33(6), 106775. https://doi.org/10.1016/j.tej.2020.106775

Shin, Y., Yu, B., \& Greenwood-nimmo, M. (2014). Festschrift in Honor of Peter Schmidt. Festschrift in Honor of Peter Schmidt. https://doi.org/10.1007/978-1-4899-8008-3

Ssali, M. W., Du, J., Mensah, I. A., \& Hongo, D. O. (2019). Investigating the nexus among environmental pollution, economic growth, energy use, and foreign direct investment in 6 selected sub-Saharan African countries. Environmental Science and Pollution Research, 26(11), 11245-11260. https://doi.org/10.1007/s11356-019-04455-0

United Nations. (2006). United Nations Fact Sheet on Climate Change - Africa. UN Climate Change Conference Nairobi 2006, (Cdm), 1-2.

Waluyo, E. A., \& Terawaki, T. (2016). Environmental kuznets curve for deforestation in Indonesia: An ARDL bounds testing approach. Journal of Economic Cooperation and Development, 37(3), 87108.

Warsame, A. A., Sheik-Ali, I. A., Ali, A. O., \& Sarkodie, S. A. (2021). Climate change and crop production nexus in Somalia: an empirical evidence from ARDL technique. Environmental Science and Pollution Research, 1-13. https://doi.org/10.1007/s11356-020-11739-3

Wheeler, D. (2011). Quantifying Vulnerability to Climate Change : Implications for Adaptation Assistance Working Paper 240 January 2011. New York.

World Bank; FAO. (2018). Rebuilding Resilient and Sustainable Agriculture in Somalia (Vol. I).

World Bank. (2018). Project Information Document / Integrated Safeguards Data Sheet (PID / ISDS ). Somali Electricity Access Project (P165497).

Zambrano-Monserrate, M. A., Carvajal-Lara, C., Urgilés-Sanchez, R., \& Ruano, M. A. (2018). Deforestation as an indicator of environmental degradation: Analysis of five European countries. Ecological Indicators, 90(February), 1-8. https://doi.org/10.1016/j.ecolind.2018.02.049

Zivot, E., \& Andrews, D. W. K. (1992). Further evidence on the great crash, the oil-price shock, and the unit-root hypothesis. Journal of Business and Economic Statistics, 10(3), 251-270. https://doi.org/10.1080/07350015.1992.10509904 
675

676

677 
Figures

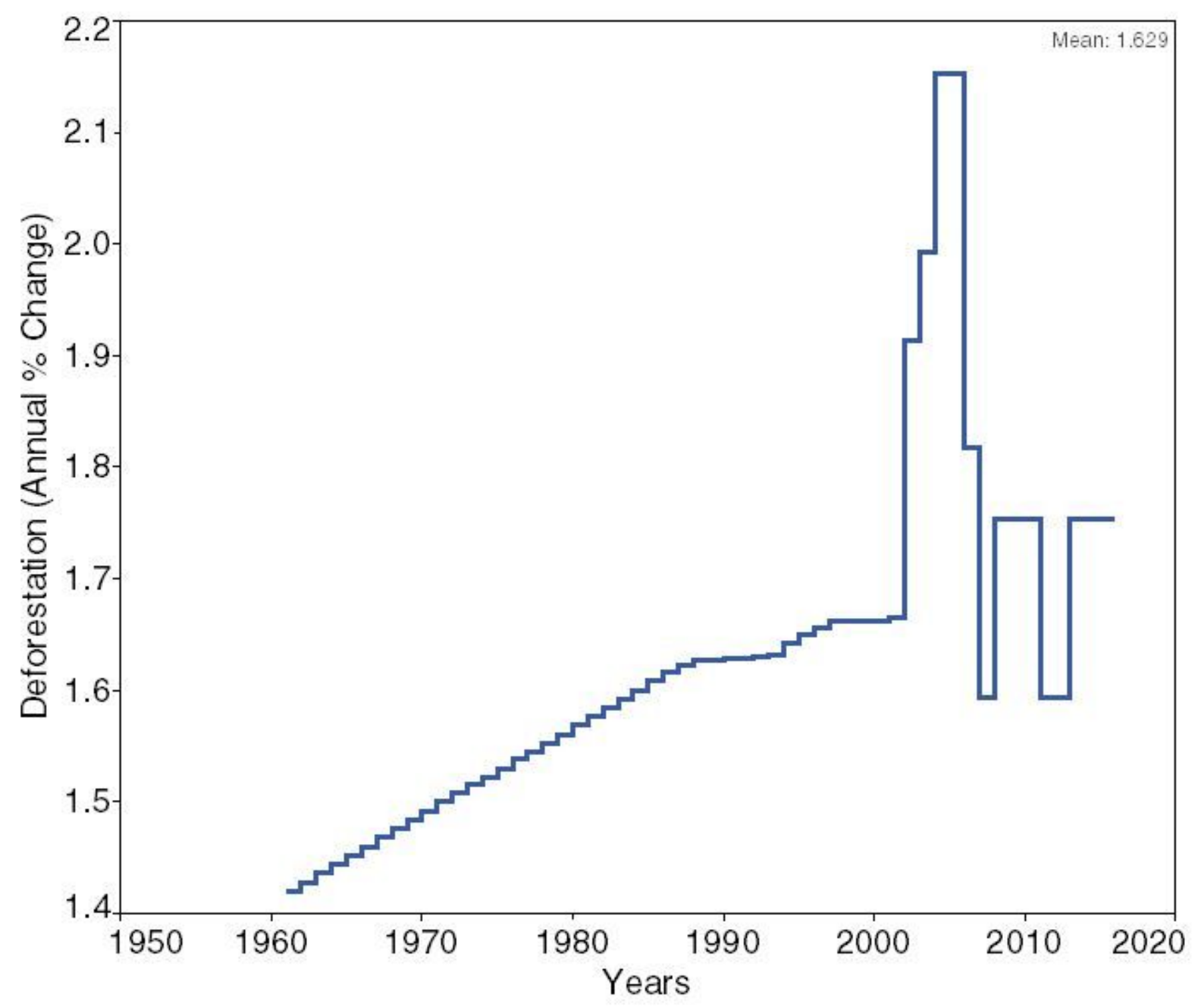

Figure 1

Annual \% Change in Deforestation. Data Source: World Bank 

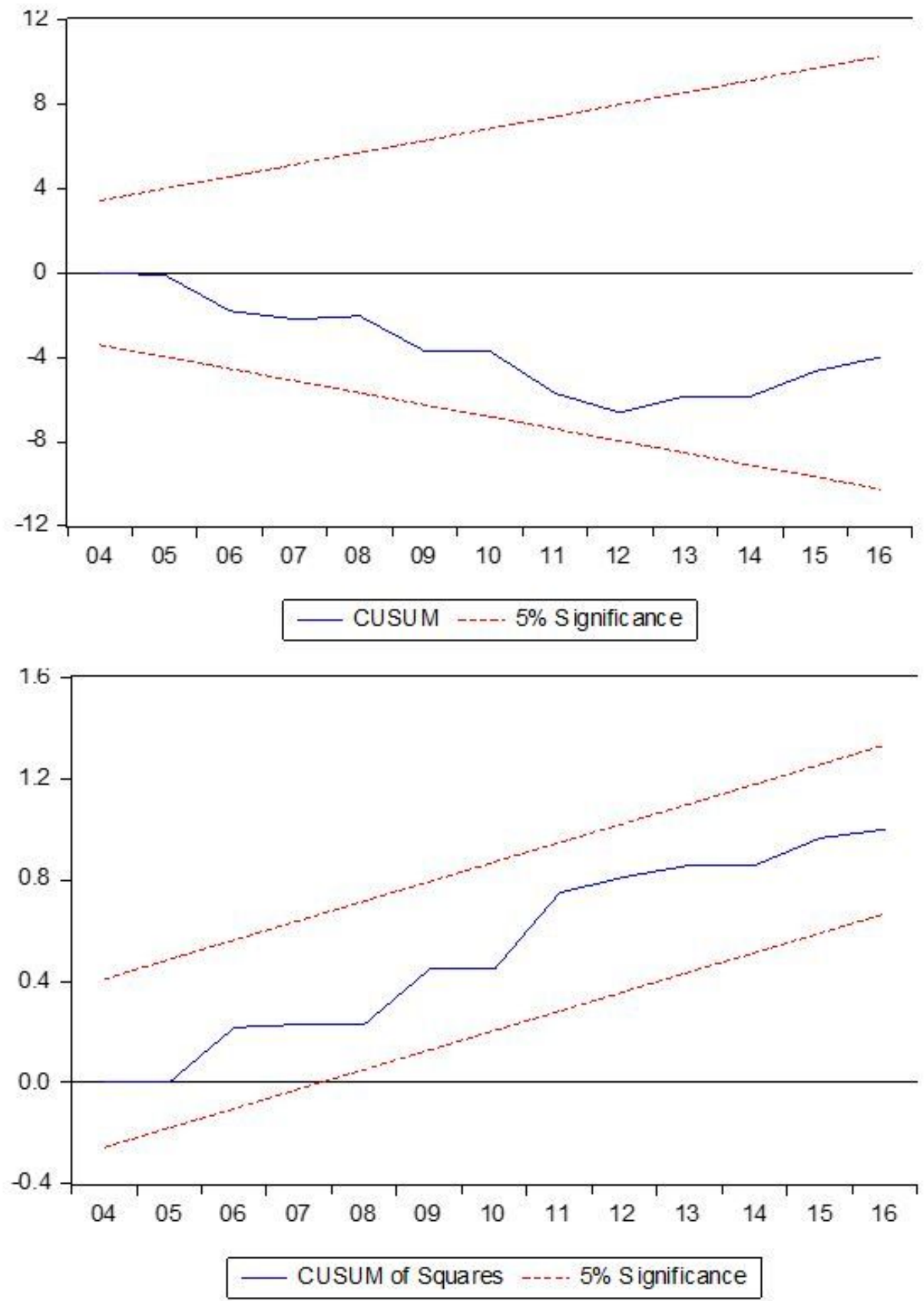

Figure 2

Model Stability (a) CUSUM Test (b) CUSUM Square Test 